\title{
Do retrospective and prospective quality of life assessments differ for pancreas-kidney transplant recipients?
}

Citation for published version (APA):

Adang, E. M. M., Kootstra, G., Engel, G. L., van Hooff, J. P., \& Merckelbach, H. L. G. J. (1998). Do retrospective and prospective quality of life assessments differ for pancreas-kidney transplant recipients? Transplant International, 11(1), 11-15. https://doi.org/10.1111/j.1432-2277.1998.tb00949.x

Document status and date:

Published: 01/01/1998

DOI:

10.1111/j.1432-2277.1998.tb00949.x

Document Version:

Publisher's PDF, also known as Version of record

\section{Please check the document version of this publication:}

- A submitted manuscript is the version of the article upon submission and before peer-review. There can be important differences between the submitted version and the official published version of record. People interested in the research are advised to contact the author for the final version of the publication, or visit the DOI to the publisher's website.

- The final author version and the galley proof are versions of the publication after peer review.

- The final published version features the final layout of the paper including the volume, issue and page numbers.

Link to publication

\footnotetext{
General rights rights.

- You may freely distribute the URL identifying the publication in the public portal. please follow below link for the End User Agreement:

www.umlib.nl/taverne-license

Take down policy

If you believe that this document breaches copyright please contact us at:

repository@maastrichtuniversity.nl

providing details and we will investigate your claim.
}

Copyright and moral rights for the publications made accessible in the public portal are retained by the authors and/or other copyright owners and it is a condition of accessing publications that users recognise and abide by the legal requirements associated with these

- Users may download and print one copy of any publication from the public portal for the purpose of private study or research.

- You may not further distribute the material or use it for any profit-making activity or commercial gain

If the publication is distributed under the terms of Article 25fa of the Dutch Copyright Act, indicated by the "Taverne" license above, 
E.M.M. Adang

G. Kootstra

G.L. Engel

J.P. van Hooff

H.L.G.J. Merckelbach

\section{Do retrospective and prospective quality of life assessments differ for pancreas-kidney transplant recipients?}

Received: 2 July 1997

Received after revision: 25 September 1997

Accepted: 10 October 1997

\section{E.E.M. Adang (ه)}

Department of I-Tealth, Organisation, Policy and Economics (BEOZ),

Faculty of Health Sciences,

Universily of Maastricht, P.O. Box 616 , 6200 MD Maastricht, The Netherlands Fax: 3143367 0960,

e-mail: Eddy.Adang@BEOZ.unimaas.nl

\section{E.M.M. Adang - G. Kootstra}

Dopartment of Surgery,

University Hospital,P.O. Box 5800,

6202 AZ Maastricht, The Netherlands

\section{G.L. Engel}

Secrelary, Board of Directors, University Flospital, P.O. Box 5800, $6202 \mathrm{AZ}$ Maastricht, The Netherlands

\section{J.P. van Hooff}

Department of Internal Medicine,

University Hospital, P.O. Box 5800,

6202 AZ Maastricht, The Netherlands

H.L.G.I. Merckelbach

Department of Psychology,

University of Maastricht, P.O. Box 616, 6200 MD Maastricht, The Netherlands

\begin{abstract}
The literature indicates that chronically ill patients have a remarkable capacity to adapt to their illness. For example, they will generally report a better quality of life (QoL) than individuals in the general population who are asked to imagine themselves as chronically ill and to rate their QoL. The present study further explotes this phenomenon in type I diabetic transplant recipients with end-stage renal disease. In a prospective, longitudinal stucly, we assessed the QoL in 22 patients, both before and after they received a combined pancreas-kidney transplant. After transplantation, the patients were also asked to assess their pretransplant QoL by rating it on a 10-point scale. What we found was that prior to transplantation, QoL was prospectively given a mean rating of 5.23; this score increased to 7 after a successful transplant procedure. During follow-up assessments 5, 12, and 18 months after successful transplantation, patients retrospectively scored their pretransplant QoL as 3.27, 3.14, and
\end{abstract}

3.05, respectively. We conclude that when type I diabetic patients with end-stage renal disease undergo a transplant procedure to improve their health status, they re-evaluate their pretransplant QoL, and this retrospective assessment is significantly lower than their prospective one when transplantation is successful.

\section{Key words Quality of life} measurement, pancreas-kidney transplantation,

adaptation - Pancreas-kidney transplantation, quality of life measurement, adaptation

\section{Introduction}

In the past few years, "quality of life" (QoL) has attracted considerable attention as an outcome parameter in clinical research [10]. One reason is the increased prevalence of chronic diseases in an aging society [4]. For these diseases, the goal of medical interventions is not to cure, but rather to improve the well-being of patients.
\end{abstract}

Not surprisingly then, in both clinical decisions and policy-making, there is a need to assess health-related QoL in an accurate way [1].

Gill and Feinstein claim that QoL is a unique, personal perception denoting the way that individual patients feel about their health status and/or nonmedical aspects of their lives [12]. Calman describes QoL as a dimension that can only be measured in individual terms 
and that depends on present lifestyle, experience, hopes for the future, dreams, and ambitions [7]. With a modest level of expectations, acceptable subjective well-being is possible, even in objectively awkward circumstances [7]. Good QoL can be said to be present when the ambitions of an individual are matched and fulfilled by experience [7]. The fact that chronically ill patients adapt to their illness may affect QoL assessments. For example, Cassileth et al. [8] found that five groups of physicaliy ill patients (suffering from arthritis, diabetes, cancer, renal disease, and dermatologic disorders) did not differ significantly from one another or from the general population in terms of their mental health scores (e.g., anxiety, depression, general positive affect, emotional ties, loss of control, or mental health index). O'Boyle et al. found results that suggest that adaptability and previous experience can substantially modify perception of QoL [20].

Adaptation can be described as a process in which past, present, and future circumstances are interpreted or evaluated in such a way that an acceptable level of well-being is achieved. It is assumed that certain events and situations can, indeed, seriously compromise the subjective feeling of well-being. However, adaptation usually takes place in due course, resulting in a level of well-being "belonging to the person" [15]. Dramatic events in the past or a decline in an individual's physical condition does not necessarily result in a reduced subjective well-being [19]. Furthermore, current problems can be put into perspective by referring to periods during which the person was worse off. Another strategy for assessing one's own situation positively is to compare oneself with others who appear to be in a more difficult situation. This phenomenon is called "downward social comparison" [21]. It is known that all people tend to believe that their future will be better than their present or their past [6]. In addition, some people greatly exaggerate the likelihood of positive outcomes in the future and judge their own outcomes as less likely than others to be negative [23]. These "positive illusions" illustrate a number of adaptive strategies and mechanisms that individuais tend to apply to restore well-being. It is plausible to assume that the relationship between adaptation and well-being is reciprocal: when a person's feeling of well-being is undermined, adaptive means are mobilized, which subsequently contribute to recuperation [15]. Heyink gives a more detailed overview of the strategies individuals use to overcome misfortune and to restore their subjective well-being [15]. He reports that chronicaliy ill patients have a remarkable capacity to adapt to their illness and will generally report a better QoL than individuals in the general population who are asked to imagine themselves under conditions of chronic illness and to rate their QoL. In fact, Tsevat et al. found that self-reported QoL of seriously ill patients is higher (i. e., better) than the patients' proxies (e. g., family members) believe them to be [22]. Fur- thermore, these authors also found that QoL, ch with time and, under normal circumstances, call considerably.

The current study explores changes in QoL rati pancreas-kidney transplant recipients. More specif we investigated whether these chronically ill pa who underwent an intervention to improve their status, in fact retrospectively lowered their pre-int tion QoL ratings. Such a pattern of QoL rating: cates that this sort of assessment reflects adaptiv cesses. It also implies that retrospective QoL sco unreliable, precisely because they underestimate pacity of chronically ill patients to adapt to their

\section{Patients and methods}

A prospective, longitudinal, multicenter study was perfo assess the QoL of 22 patients with type I diabetes and endnal disease, both before and after they received a combir creas-kidney transplant that functioned for at least $5 \mathrm{mom}$ transplantation [2]. In addition, patients were asked po plantation to evaluate their pretransplant QoL. The stud was from June 1992 lo January 1994. In this study a : transplant procedure was defined as one that resulted in neys and pancreas functioning properly $(n=17)$ or in the being rejected soon after the transplantation $(n=5)$.

The present study was part of a larger research projec evaluation $[2,3]$. This project was approved by the etlices tec. All patients gave their informed consent prior to th sion in the study.

The patients were interviewed at their homes prior plantation (baseline) and at 5, 12, and 18 months post-tra tion. Each time they were asked to assess their current $Q$ ing it on a 10-point visual analogue scalc (VAS) on whic sented "worst imaginable QoL" and 10 "best imaginal During the three post-transplant follow-ups, the patio asked to estimate their pretransplant QoL.

There were several reasons for choosing to use VAS an index of QoL, among them the fact that a VAS is eas stand and requires very little time. Moreover, according and Kane [11], VAS ratings are one of the most promisin struments in terms of reliability, validity, and feasibility ingly, VAS ratings are widely used in QoL research [ 11 ,

In the current study, the QoL assessment (i. e., the VA troduced to patients as a subjective way of assessing on health. To examine to what extent QoL ratings are rela eral well-being and future expectations, patients were to complete the Affect Balance Scale (ABS) $[5,9]$ and a question about these future expectations.

The ABS was chosen because it yields an overal score that is a good index of general well-being $[2,5$, thermore, according to Gill and Feinstein, the ABS available indicator of well-being when it is applied alo subjective rating scale, similar to the VAS in the pro [12]. The ABS questionnaire includes ten questions abc and negative affects that are evaluated in terms of abso present (" 1 "). Interpretation of the ABS score is as score below 2 indicates general well-being that is less th a score of 2 is average, and a score above 2 is above 9].In this study, a validated form of a Dutch version was used [9]. The prospcctive VAS and ABS scores 
Table 1 Mean VAS scores and standard deviations (SD) pre- and post-transplantation

\begin{tabular}{lll}
\hline Assessment of current QoL & Mean & SD \\
\hline Pretransplantation (baseline) & 5.23 & 1.82 \\
At 5 months post-transplantation & $7.05^{*}$ & 1.40 \\
At 12 months post-transplantation & $7.62^{*}$ & 1.28 \\
At 18 months post-transplantation & $7.40^{* *}$ & 1.50 \\
Retrospective assessment of pretransplant QoL & & \\
At 5 months post-transplantation & $3.27^{* * *}$ & 1.91 \\
At 12 months post-transplantation & $3.14^{* * *}$ & 1.93 \\
At 18 months post-transplantation & $3.05^{* *}$ & 2.24 \\
\hline
\end{tabular}

* $P<0.000$ (significant increase; within measurements, $d f=57$, 14.94);

w* $P<0.000$ (significant decreasc; within measurements, $d f=57$, 14.27)

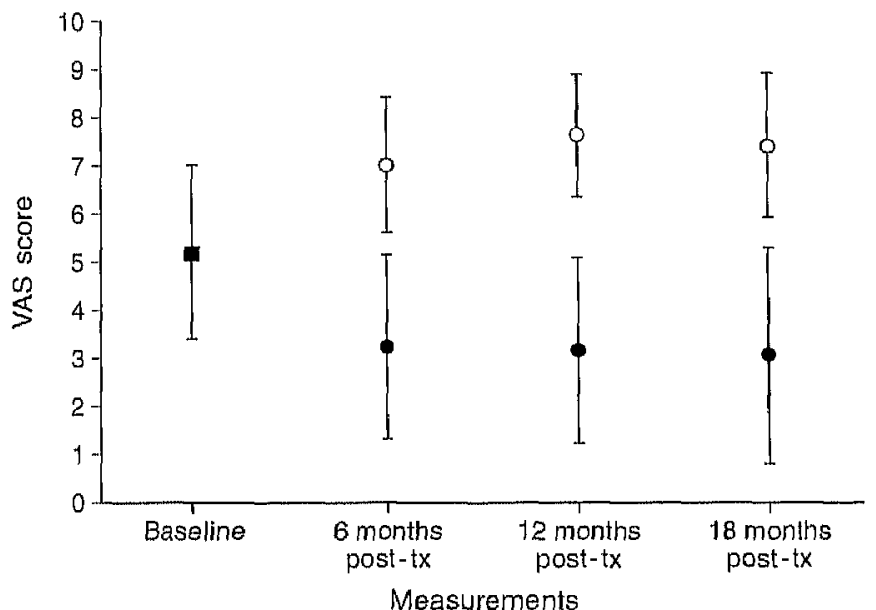

Fig. 1 Prospective and retrospective VAS scores presented as means and standard deviations. Retrospective; $\bigcirc$ prospective

5,12 , and 18 months after transplantation) were expected to correlate positively [12]. However, when patients retrospectively assess their baseline QoL differently after an intervention, these retrospective scores do not generally corrclate with the bascline ABS score. During baseline and prospective assessments, paticnts were also asked "When you consider the future, what state do you expect your health to be in 1 year from now?" in order to examine whether future expectations affect retrospective and prospective QoL assessments.

VAS scores were tested for normality with a Kolmogorov-Smirnov test. Data were expressed as means and standard deviations (SD). A repeated-measures ANOVA (within measurements) was used to test the null hypothesis that pretreatment QoL ratings do not differ from retrospective, post-treatment ratings. Conservative criteria for statistical significance were applied, and standard Bonferroni correction was used. The null hypothesis (i.e., that the three retrospective, post-trcatment VAS scored would not differ from each other) was tested using the same approach. Finally, we examined whether prospective QoL assessment was higher posttransplantation. Due to their ordinal character, differences in patients' expectations over the time were tested nonparametrically with a Wilcoxon matched-pairs signed rank test. The correlation between VAS and ABS was investigated by calculating Pearson correlations. Data were analyzed with SPSS, version 6.1 .

\section{Results}

Two patients with a pancreas and kidney functioning at 5 months post-transplantation were not able to finish the study. One patient suffered from a stroke and could not be interviewed after 12 months, and the other died before 18 months had passed. Overall, VAS scores had a normal distribution. Table 1 shows the mean VAS scores pre- and post-transplantation. The QoL on the VAS was prospectively assessed as 5.23 at baseline and increased significantly to over 7 after successful transplantation $(P<0.001$; Table 1, Fig. 1). At 5, 12, and 18 months after successful transplantation, patients retrospectively assessed their pretransplant QoL as 3.27, 3.14 , and 3.05, respectively (Table 1, Fig. 1). On the basis of these data, the null hypothesis could be rejected $(P<0.001)$. Parameter estimation showed a strong linear trend (coefficient $=-1.755, t=4.803 ; P<0.001$ ). The three retrospective post-transplant ratings did not differ significantly from each other $(P=0.405$; Table 1$)$ [3].

The retrospectively assessed baseline VAS scores did not correlate with the baseline ABS score $\left(r_{5}\right.$ momllws $\left.=-0.076, \quad r_{12 \text { months }}=-0.113, \quad r_{18 \text { months }}=-0.100\right)$. The prospective VAS scores correlated moderately with the ABS scores $\left[r_{\text {haseline }}=0.297, r_{5 \text { momlls }}=0.575(P<\right.$ $0.01) ; r_{12 \text { month } 1.5}=0.484(P<0.05) ;$ and $r_{78 \text { monthls }}=0.477$ $(P<0.05)]$. Patients' ABS scores increased from 2 at baseline to 3.5 after transplantation, although this improvement was not significant $(P=0.1579)$. Patients' expectations with regard to their future health (Table 2) changed significantly over time [Wilcoxon matchedpairs signed rank test; $\mathrm{Z}=-2.4962$ (12 months) and $\mathrm{Z}=$ -2.3094 (18 months, $P<0.05$ )], with $59.1 \%$ of them believing in improvement before transplantation and $35 \%$ believing in improvement at 12 and 18 months after transplantation. Table 2 suggests that the data are similar for baseline and 5 months, and similar for 12 and 18 months, with the latter two measurements differing from the former two measurements.

\section{Discussion}

The most important finding of the present study is that prospective QoL assessments differ considerably from those made retrospectively. Patients who underwent a successful transplant procedure underestimated their previous self-reported baseline QoL score. From a psychometric persective, this finding underlines the critical difference between QoL ratings pertaining to the current situation and those pertaining to a previous period. 
Table 2 Patients' expectations regarding the state of their future health. Question: "When you consider the future, what do you expect your health to be like in 1 year?"

\begin{tabular}{llll}
\hline Point in time & $\begin{array}{l}\text { Pretrans- } \\
\text { plantation }\end{array}$ & $\begin{array}{l}5 \text { Months } \\
\text { post-trans- post-trans- post-trans- } \\
\text { plantation plantation plantation }\end{array}$
\end{tabular}

Answer: I

expect it to:

\begin{tabular}{lllll}
\hline improve & $13(59.1 \%)$ & $14(63.6 \%)$ & $8(38.1 \%)$ & $6(30 \%)$ \\
rcmain the same & $5(22.7 \%)$ & $5(22.7 \%)$ & $12(57.1 \%)$ & $13(65 \%)$ \\
worsen & 0 & 0 & 0 & 0 \\
I cannot tell & $4(18.2 \%)$ & $3(13.6 \%)$ & $1(4.5 \%)$ & $1(5 \%)$ \\
\hline
\end{tabular}

Data expressed as absolute numers an (percentages)

One could question whether a difference of about two points (i.e., the difference between 5.23 and 3.05) on the VAS is a clinically relevant difference. When one considers that two points on the VAS represents the difference between being on dialysis or having a perfectly healthy kidney and, in most cases, a functioning pancreas (i.e., the difference between 5.23 and 7.62), one should conclude that a two-point difference on the VAS is, indeed, very clinically relevant [2]. However, it should be noted that this is only true when the VAS is at least interval-scaled, which is assumed.

From these findings, one may conclude that studies that retrospectively assess QoL in chronically ill patients lead to different conclusions than studies based on prospective assessments of QoL. A likely explanation for this phenomenon is adaptation to illness during the pretransplant period [3]. It is reasonable to assume that patients' expectations regarding the state of their health at baseline were heightened because of the prospect of a cure for both nephropathy and diabetes. Thus, one could argue that expectations about one's future health influence the baseline QoL score. Yet, there appears to be hitthe or no difference with regard to these future expectations between the pretreatment and 5-month post-treatment evaluations, even though the QoL scores differ. Presumably, this difference in VAS score is related to a change in health status and not to future expectations. In addition, serial QoL assessments after transplantation do not seem to reflect any dramatic changes in future expectations about the state of the patients' health (Tables 1,2). As stated earlier, adaptation refers to strategies that individuals use to overcome misfortune and to restore their subjective well-being. A shift in one or several of these strategies will change the perceived, retrospective QoL after transplantation. If, due to the transplantation, a patient's attitude towards the adaptive strategies changes, the patient's assessment of his QoL cannot be interpreted properly. This is because the post-transplantation patient operates as a differently calibrated person with regard to adaptational strategies. This response shift [15], rather than future expectations or well-being, provides an explanation for the differen between current and retrospective assessments of Qol

Kiebert et al. [17] used the VAS in a retrospecti cross-sectional study with a similar patient group (ty I diabetic patients with end-stage renal disease). Th found that, after an unsuccessful transplantation (rej tion of both pancreas and kidney), patients tend (o) rospectively upgrade their perception of their QoL fore transplantation. In contrast, the present resu show that, after a successful transplantation, patic underestimate their baseline QoL. Thus, it secms II variations in QoL are outcome-dependent.

Several studies have assessed the ability of resp dents to recall their state of health when the same in viduals are asked identical questions at a later lime 14, 16, 18]. Herrmann [14] acknowledged recall bits a possible distortion factor in retrospective designs. I ward et al. [15] have referred to this re-evaluation it retrospective pretest, and to the re-evaluation as a sponse-shift effect. The sample in which they investig ed this phenomenon was one consisting of undergrat ate students and not of chronically ill patients. lior reason, the results of their study are difficult to gene ize to the present context. Mancuso and Chatlison I found results similar to those in our study. Their patic had undergone total hip replacement, but the effeet interpreted as recall bias. Mancuso and Charlsom sought to determine whether there were systemallic ases to the disagreement between actual ancl recal status. Their results showed that there were difleren in the number of patients who had recollection ent for the different domains. No trend of systematic was found, and the magnitudes of the biases were the same within a sub-group. This contradicts our I ings, in which parameter estimation showed a strung ear trend of systematic bias and a small standard de tion of the results within the study group. Adirpliat rather than recall bias, is a plausible explanation for results of the present study.

Recently, Guadagnoli and Cleary [13] conclucled a change in one's health does not depend upon whe a baseline assessment was recalled or made prior I intervention. These results are difficult to recol with the present results. However, one must be mind that Guadagnoli and Cleary were studying tients with acute myocardial infarction, whereas the sent study involved chronically ill, insulin-depen patients with end-stage renal disease. Palienls have insulin-dependent diabetes and end-stinge disease are worried about their well-being, but als goes by, this impaired well-being leads to a decre: the patients' internal standard against which the di is evaluated [20]. In other words, time is a great he Thus, one cannot expect acute patients and chiou ill patients to adapt in the same way. Mancuso Charlson's findings [18] underline this fact. 
Finally, it should be pointed out that this study suffers from a few methodological limitations. The sample size is small, due to a highly specialized nature of the intervention, which is not often carried out, and the fact that few patients met the inclusion criteria for the procedure. Because of this small sample size, a conservative statistical approach towards significance was used. It should also be noted that a patient's ability to recall prior functioning can vary, depending on the type of scale employed. In this study, only a VAS was used to assess the QoL. It should be emphasized that the VAS is a subjective, single-index measure incorporating all aspects of QoL from a specific patient's point of view. With a VAS one cannot distinguish between certain specific do- mains of QoL, such as social and emotional functioning, and symptoms.

Nevertheless, these limitations do not invalidate the conclusion that can be drawn from the current results, namely, that retrospective QoL assessment does not reflect the patient's subjective state to which retrospective measurements refer.

Acknowledgements We gratefully acknowledge the following colleagues who made it possible for us to have access to their patients: A. M. Tegzess, University Hospital Groningen; F. J. van der Woude, University Hospital Leiden; Y. Vanrenterghem, Universily Hospital Gasthuisherg, Leuven (Belgium): J.P. van Hooff', University Hospital Maastricht; R. A. P. Kocne, University Hospital Nijmegen.

\section{References}

1. Adang EEM, Ament A, Dirksen CD (1996) Medical technology assessment and the role of economic cvaluation in health care. J Evaluation Clin Practice 2: $287-294$

2. Adang EEM, Engel GL, Hooff JP van, Koolstra G (1996) Comparison prior to and after transplantation of pancreaskidney and pancreas-kidney with loss of pancreas. Transplantation 62: 754-758

3. Adang EEM, Kootstra G, Baeten CGMI, Engel GL (1997) Quality of life ratings in patients with chronic illnesses. JAMA 277: 1038

4. Bos GAM van den, Limburg LCM (1995) Public health and chronic diseases. Eur J Public Health 5: 1-2

5. Bradburn NM (1969) The structure of psychological well-being. Aldine, Chicago, p 59

6. Brickman P, Coates D, Janolf-Bulman R (1978) Lottery winners and accident. victims: is happiness relative? J Pers Soc Psychol 36: 917-927

7. Calman KC (1984) Quality of life in cancer patients - an hypothesis. J Med Ethics 10: 124-127
8. Cassileth BR, Lusk EJ, Strouse TB, Miller DS, Brown LL, Cross PA, Tenaglia AN (1984) Psychosocial status in chronic illness: a comparative analysis of six diegnostic group. $\mathrm{N}$ Engl J Med 311: 506-511

9. Centraal Bureau Statistick (1983) Leefsituatie Nederland: kerncijfers. p 87

10. Eclitorial (1995) Quality of life. Lancet 346: $1-2$

11. Froberg DG, Kane RL (1989) Methodology for measuring health-stale preferences. II: scaling methods. J Clin Epclemiol 5: 459-471

12. Gill TM, Feinstcin AR (1994) A critical appraisal of the quality of life measurements. JAMA 272: 6j9-626

13. Guadagnoli E, Cleary PD (1995) How consistent is pationt-reported pre-actmission health status when collected during and after hospital stay? Med Care 33: 106-112

14. Herrmann D (1995) Reporting current, past, and changed health status. What we know about distortion. Med Care 33:AS89-AS94

15. Heyink J (1993) Adaptation and wellbeing. Psycliol Rep 73; 1331-1334

16. Howard GS, Dailey PR, Gulanick NA (1979) The feasibility of informed prelests in attenuating response-shift bias. Appl Psychol Meas 3: 481-494
17. Kiebert GM, Oosterhout ECAA van, Bronswijk HI van, Lemkes HIIPJ, Gooszen HG (1994) Quality of life a[ter combinde kidney-pancreas or kiclncy transplantation in diabelic patients with end-stage renal disease. Clin Transplant 8: 239-245

18. Mancuso CA, Charlson ME (1995) Does recollection error threaten the valiclity of cross-sectional studies of clfectiveness? Med Cnre 33;AS77-AS88

19. Najman J, Levine S (1981) Evaluating the impact of medical care and technologies on the quality of life: a review and critique. Soc Sci Med 1.5F:107-1.15

20. O'Boyle CA, McGee H, Hickey A. O'Malley K, Joyce CRB (1092) Individual quality of life in patients undergoing hip replacement. Lancet 339: $1088-1091$

21. Taylor SE (1983) Adjustment to threatening cvents. Am Psychol 38: 1161-1 173

22. Tseval J, Cook EF, Green ML (1995) Health values of the seriously ill. Ann Inter'n Med 122: 514-520

23. Weinstein ND (1980) Unrealistic optimism about future life events. J Pers Soc Psychol 39: 806-820) 